\title{
Language for a polyglot readership
}

\author{
What are the reasons why the English-language literature of science is understood only with difficulty elsewhere? \\ And what might make it more accessible?
}

IN June last year, this journal carried a photograph of a lion on its front cover to mark the publication of a Letter referring, among other things, to the determination of the status of a lion within the pride to which it belongs. It seemed natural, even smart, to add to the illustration of the lion the caption "Prides and prejudice": 'pride' is the collective noun for a group of lions, and Pride and Prejudice is the title of a novel by Jane Austen, arguably the second-best of all British women novelists. But more recently, a Japanese journalist complained to a colleague at the caption, explaining that his translation machine, essentially an EnglishJapanese dictionary, could make no sense of "Prides and prejudice".

A little thought should have shown us quickly why this caption would mean very little to a computer program designed to help Japanese to read English. The sobering thought is that the same caption may also have meant very little to anybody who happened not to know either the collective noun for lions nor the title of Jane Austen's novel, many of whom may shamefully have been English speakers, perhaps even Britons. Technically, the fault with the caption is that it is a play on words whose meaning may have been clear to a small section of Nature's readership, but mystifying to most.

Allusions are not in themselves impediments to understanding. When they are understood, they may shorten an argument or enrich its associations. But when they are not understood, they are worse than useless, but are puzzling, confusing and distracting. It is therefore of some importance to know where to draw the line between acceptable and unacceptable allusions.

Thus the sentence "A small step for DNA sequencing, a giant step for ReddyKwik Inc." will usually require no further parsing. ReddyKwik is telling its customers that it believes its latest new product to mark the beginning of a new era in its commercial history, and that it also wishes to invest the development with the sense of occasion attending Neil Armstrong's first walk on the Moon. But even that allusion may fall flat, for example in the former Soviet Union. Its effect will also fade as time passes.

Some allusions to classical history also 'travel', as people in the advertising industry sometimes say. 'Herculean' is, for example, an adjective in English and many other languages, although Augean is not, requiring readers to know that one of the tasks imposed on Hercules was to clean the Augean NATURE · VOL 359 • 8 OCTOBER 1992 stables. Biblical allusions must be used with care. Would 'Noah' feature in the Japanese journalist's translation machine? Why should the tale of Adam and Eve be better known in India than the tale of Lord Krishna is known in Western Europe? And it would be asking too much of readers' imagination to be told of a person who had changed his opinion of the beneficial effects of megadoses of vitamin C that "Palo Alto [the Californian town near which Linus Pauling lives] was his Damascus"; St Paul's conversion on the road to that city is a part of general knowledge in what is loosely called Christendom; elsewhere, it is not.

For a journal such as this, whose readers include perhaps 40 per cent for whom English is not their first language, allusive writing is a disservice and should usually be avoided. In any case, it would be unreasonably immodest to claim that allusive writing is commonplace in Nature or that it substantially enriches any group of readers' understanding.

This is one of the conclusions that might have been reached at a meeting of Nature's senior editorial staff a few days ago. It is part of an answer to one of several questions of editorial policy: how to make an international journal more accessible to a polyglot audience. The question is more easily asked than answered.

Not that it is difficult to specify other categories of usage that deserve as much caution as allusions. Slang, for example, which some would ban on aesthetic or even doctrinal grounds, is notoriously illtravelled and impermanent. Cliches are in the same case; it is likely that only in Britain do politicians include the phrase "at the end of the day" (meaning "ultimately', 'eventually' or 'in the end') in every other sentence; it is to be hoped that even they will soon let the practice lapse.

Unfortunately, these restrictions (desirable for other reasons) are not a solution to the general problem, whose roots lie elsewhere. And it is worth recalling that, not so long ago, an article in this journal demonstrated that even English-speaking readers would find the vocabulary of articles and letters in Nature substantially more difficult than that in some comparable and most generally circulating publications (Nature 356, 739-740; 1992).

That should not necessarily apply to the parts of this journal that are written or at least controlled by the editorial staff, but some features of scientific prose seem to be infectious, notably the habit of forming portmanteau adjectives (such as 'DNAdependent cytosol-controlled' as a qualifier of 'polymerase', if there is such a thing). English-speaking readers get used to these adjectives, but others have to unravel their meaning at every encounter.

But even simply structured words can make difficulties. Nature has tried over the years to contribute to a solution of the difficulty of vocabulary by choosing one of several alternative words with the same meaning. When 'while' and 'whilst' have the same meaning, will it not simplify a reader's understanding to settle for the first and to ban the second? To some degree, perhaps, but only to a marginal degree.

The underlying dilemma is that it is not possible to go too far in this direction without making prose sound like baby-talk. People in the trade are not put off by words such as 'asymptotic' (not to be confused with 'asymptomatic'), but it would serve no purpose for even non-English-speaking readers to translate them into simpler language. It is not in the vocabulary of science that the difficulty lies, but in the general vocabulary that holds it together.

Sentence structure is the other great impediment to understanding. The last sentence of the preceding paragraph, for example, begins with a passive clause whose effect is to dramatize the distinction between the two vocabularies, but which would probably have provided non-Englishspeaking readers with greater difficulty. Whether that is worthwhile is an open question.

These are interesting and important questions. Nature is anxious to improve its own performance and, in the process, to make the journal more accessible to its polyglot readership without diminishing such pleasure as its readers at present win from what it prints. There cannot be an absolute impediment to the improvement of the clarity of the text as perceived by people in different places. Probably the guiding principle is that if a text is clear in English (or, for that matter, in French), that it will also be more intelligible in Japanese.

Little is known about the practical impediments to polyglot understanding. Nature would be glad to hear from interested readers who believe they have something to contribute to the better understanding of the text in the front sections of the journal. And the remainder of the text? That is a different and more formidable problem which already engages many people's working attention. John Maddox 